\title{
Nested hollow architectures of nitrogen-doped carbon-decorated Fe, Co, Ni-based phosphides for boosting water and urea electrolysis
}

\author{
Jie Zhang ${ }^{1, \S}$, Shoushuang Huang ${ }^{1, \S}(\bowtie)$, Ping Ning ${ }^{1}$, Peijun Xin ${ }^{1}$, Zhiwen Chen $^{1}(\bowtie)$, Qing Wang ${ }^{1}$, Kajsa Uvdal $^{2}$, and \\ Zhangjun $\mathrm{Hu}^{1,2}(\triangle)$ \\ ${ }^{1}$ Shanghai Applied Radiation Institute, School of Environmental and Chemical Engineering, Shanghai University, Shanghai 200444, China \\ ${ }^{2}$ Division of Molecular Surface Physics \& Nanoscience, Department of Physics, Chemistry and Biology, Linköping University, Linköping 58183, \\ Sweden \\ § Jie Zhang and Shoushuang Huang contributed equally to this work.
}

(C) The Author(s) 2021

Received: 7 June 2021 / Revised: 2 August 2021 / Accepted: 11 August 2021

\begin{abstract}
Tailoring the nanostructure/morphology and chemical composition is important to regulate the electronic configuration of electrocatalysts and thus enhance their performance for water and urea electrolysis. Herein, the nitrogen-doped carbondecorated tricomponent metal phosphides of $\mathrm{FeP}_{4}$ nanotube@Ni-Co-P nanocage (NC-FNCP) with unique nested hollow architectures are fabricated by a self-sacrifice template strategy. Benefiting from the multi-component synergy, the modification of nitrogen-doped carbon, and the modulation of nested porous hollow morphology, NC-FNCP facilitates rapid electron/mass transport in water and urea electrolysis. NC-FNCP-based anode shows low potentials of $248 \mathrm{mV}$ and $1.37 \mathrm{~V}$ (vs. reversible hydrogen electrode) to attain $10 \mathrm{~mA} / \mathrm{cm}^{2}$ for oxygen evolution reaction (OER) and urea oxidation reaction (UOR), respectively. In addition, the overall urea electrolysis drives $10 \mathrm{~mA} / \mathrm{cm}^{2}$ at a comparatively low voltage of $1.52 \mathrm{~V}$ (vs. RHE) that is $110 \mathrm{mV}$ lower than that of overall water electrolysis, as well as exhibits excellent stability over $20 \mathrm{~h}$. This work strategizes a multi-shellstructured electrocatalyst with multi-compositions and explores its applications in a sustainable combination of hydrogen production and sewage remediation.
\end{abstract}

\section{KEYWORDS}

tri-metal phosphides, nested hollow nano-architecture, oxygen evolution reaction, urea oxidation reaction

\section{Introduction}

Hydrogen energy has been consumingly regarded as one of the foremost alternatives for unsustainable fossil fuels on account of the ever-increasing energy demand and the rising concerns about environmental issues [1-3]. Nowadays, water electrolysis is a promising technology to obtain renewable hydrogen energy $[4,5]$. However, the anodic oxygen evolution reaction (OER), as the paramount half-reaction of water splitting, is a kinetically sluggish process and requires a fairly high overpotential due to the formation of high energy intermediates in the multi protoncoupled electron-transfer process [5-7]. This could be addressed by using anodic reactions based on other substances e.g., hydrazine [8], benzylamine [9], methanol [10], ethanol [11] and urea $[12,13]$, which are more prone to be oxidized than water molecules. Among there, the anodic urea oxidation reaction (UOR) is preferable because urea electrolysis requires a low potential to produce hydrogen and enables urea-rich sewage remediation. In alkaline electrolysis, the theoretical voltage $(0.37 \mathrm{~V}$ vs. reversible hydrogen electrode (RHE)) of UOR is much lower than that of OER (1.23 V vs. RHE) [14,15]. Therefore, urea electrolysis potentially enables a sustainable combination of pollution treatment and energy conversion. To achieve efficient water and urea electrolysis, noble-metal catalysts with their low overpotentials and high proton mobility, e.g., $\mathrm{IrO}_{2}$ and $\mathrm{RuO}_{2}$, display excellent electrocatalytic performance [16]. Unfortunately, the scarcity and excessive costs limit their larger-scale application in industry. Therefore, the development of electrocatalysts with high efficiency, low cost, and high abundance is still urgent and challenging.

To date, transition metal phosphides (TMPs), such as $\mathrm{Ni}_{2} \mathrm{P}[17$, 18], $\mathrm{Fe}_{2} \mathrm{P}$ [19], MoP [20] and CoP [21] have been attracted wide attention owing to their chemical stability, low-cost, and environmental friendliness [22]. Among them, nickel phosphide shows extraordinary electrocatalytic activity and stability for UOR $[17,19,23]$. Both experimental results and density functional theory (DFT) calculations have been demonstrated that the highvalence nickel species generated during the catalysis process plays a key role in improving the UOR activity $[1,19,24]$. Nonetheless, the inappropriate electronic structure and poor electronic conductivity still hinder the further improvement of catalytic activity of nickel-based electrocatalysts [23]. Thus, exploring effective approaches to overcome these defects has become the most critical step to improve the performance of Ni-based phosphides. 
In recent years, a variety of effective strategies have been used to boost the electrocatalytic activity of nickel-based catalysts, such as improving intrinsic activity by multi-metallization [25], exposing more active sites by modulation of nanostructures and morphologies [20] as well as enhancing electrical conductivity with the conductive matrix [19]. Thereinto, multi-metallization that incorporates one or more transition metals with a similar atomic radius and electron configuration into the host metal atoms is an effective strategy [24]. The interactions among different metal elements can effectively modulate the electronic structure of the $3 \mathrm{~d}$ orbital, optimize the free energy of adsorption of the intermediates, and improve the electrocatalytic OER or UOR activity [26,27]. For instance, Wang et al. fabricated heterometallic phosphide nanobox Co-Ni-Fe-P, which exhibited a remarkable OER activity with the abundant active sites and the optimized valence electrons [2]. Sha et al. prepared thorny leaf-like $\mathrm{NiCoP}$ via the in situ vertically grown on a carbon cloth (NiCoP/CC), which confirmed that the incorporation of Co into nickel-based phosphates can tune the electronic structure around $\mathrm{Ni}$ and $\mathrm{P}$ elements, enhance the charge transfer rate, and reduce the kinetic energy barriers in the UOR process [24]. These demonstrated that the corporation of $\mathrm{Fe}$ and $\mathrm{Co}$ that belong to the same group as $\mathrm{Ni}$ into Ni-based phosphides could optimize the electronic structure of the material, facilitate the formation of highenergy intermediates $\left(\mathrm{OOH}^{*} / \mathrm{CO}^{*} / \mathrm{NH}_{2}^{*}\right)$ and accelerate the combination of the adsorbed hydrogen intermediates $\left(\mathrm{H}^{\star}\right)$ into $\mathrm{H}_{2}$ [28-31]. However, there is still a severe challenge to produce multicomponent TMPs with more accessible active sites and enhanced electron conductivity.

Structural and morphological modulation is now a popular and efficient way to maximize the exposure of active sites for boosting the activity of electrocatalysts [32-34]. Three-dimensional (3D) hierarchical hollow architectures have attracted great attention as they provide a larger surface area and better utilization of the sites from inner space for fast electron/mass transport [35]. Hitherto, different types of TMPs, e.g., multi-shelled $\mathrm{Ni}_{2} \mathrm{P}$ [36], CoP@FeCoP/NC [37], FeCo-FeCoP@C [38] and CoP/NiCoP [39] have been fabricated and studied. Therein, metal-organic frameworks (MOFs) have been demonstrated as promising precursors to construct multi-shelled hollow architectures owing to the features of large specific surface areas, multi-porous hierarchical structures, diverse compositions, and well-defined metal centers [40-43]. For instance, Lou et al. reported $\mathrm{Co}_{3} \mathrm{O}_{4} / \mathrm{NiCo}_{2} \mathrm{O}_{4}$ double-shelled nanocages that were controllably transformed from ZIF-67/Ni-Co layered double hydroxide (LDH) [44]. In addition, Wang et al. demonstrated that ZIF-67/Ni-Co $\mathrm{LDH}$ is a rational intermediate to achieve conductive nitrogendoped carbon decoration of phosphides without the damage of nanocage structures [45]. Importantly, during the phosphating process of $\mathrm{Ni}-\mathrm{Co} \mathrm{LDH}$, the $\mathrm{Ni}-\mathrm{Co} \mathrm{LDH}$ nanosheets were converted to the Ni-Co-P nanoparticles and the assembly of the interlinked Ni-Co-P nanoparticles resulted in abundant pores, which could facilitate rapid electron/mass transport for the electrocatalysis [29].

Inspired by the abovementioned works, herein, we fabricate multi-component Fe-, Co-, and Ni-based phosphides as electrodes for efficient OER and UOR through a facile approach. Through the rational designs, $\mathrm{Fe}_{2} \mathrm{O}_{3}$ nanotube, $\mathrm{Fe}_{2} \mathrm{O}_{3}$ nanotube@ZIF-67, and $\mathrm{Fe}_{2} \mathrm{O}_{3}$ nanotube@Ni-Co LDH are successively produced as the precursors to achieve the final nested hollow nitrogen-doped carbon-decorated $\mathrm{FeP}_{4}$ nanotube@Ni-Co-P nanocage (NCFNCP). The synergistic interplay of multiple catalytic centers $(\mathrm{Ni}$, $\mathrm{Co}$, and $\mathrm{Fe}$ ) provides proper electronic structure and local coordination environment improving the electrocatalysis performance for water and urea electrolysis. Additionally, the nested double hollow structures of NC-FNCP facilitate the release of evolved gas bubbles that can activate the reaction interface and promote the adsorption of important intermediates. And the nitrogen-doped carbon can further accelerate the electron transfer rate. Therefore, the as-prepared NC-FNCP electrode exhibits great properties on both the OER and the UOR, with the potentials of $248 \mathrm{mV}$ and $1.37 \mathrm{~V}$ to attain a current density of $10 \mathrm{~mA} / \mathrm{cm}^{2}$, respectively. In addition, NC-FNCP shows great overall water and urea splitting performance and long-term stability.

\section{Experiment}

\subsection{Materials synthesis}

\subsubsection{Synthesis of $\mathrm{Fe}_{2} \mathrm{O}_{3}$ nanotubes}

All reagents were used directly after receipt without further purification. The synthesis of $\mathrm{Fe}_{2} \mathrm{O}_{3}$ nanotubes followed the previous work $[46,47]$. In a typical procedure, $3.2 \mathrm{~mL}$ of $\mathrm{FeCl}_{3}$ $(0.5 \mathrm{~mol} / \mathrm{L})$ and $2.88 \mathrm{~mL}$ of $\mathrm{NH}_{4} \mathrm{H}_{2} \mathrm{PO}_{4}$ solutions $(0.02 \mathrm{~mol} / \mathrm{L})$ were mixed. Subsequently, deionized (DI) water was poured into the above solution to reach a total volume of $80 \mathrm{~mL}$ under stirring. The mixed solution was then sealed into a $100 \mathrm{~mL}$ Teflon-lined autoclave and maintained at a preheated oven at $220{ }^{\circ} \mathrm{C}$ for $48 \mathrm{~h}$. After the Teflon-lined autoclave cooled down naturally, the product was collected by centrifugation and repeatedly rinsed with deionized water and ethanol three times, and finally dried at $60^{\circ} \mathrm{C}$ in an oven.

\subsubsection{Synthesis of $\mathrm{Fe}_{2} \mathrm{O}_{3}$ nanotube@ZIF-67 nanocomposite structure}

Typically, $1.2 \mathrm{~g}$ polyvinylpyrrolidone (PVP) was dispersed in 50 $\mathrm{mL} \mathrm{Fe} \mathrm{O}_{3}$ methanol mixture, and stirred at room temperature for $15 \mathrm{~min}$, then maintained for about $10 \mathrm{~min}$. The $50 \mathrm{~mL}$ cobalt nitrate hexahydrate $\left(\mathrm{Co}\left(\mathrm{NO}_{3}\right)_{2} \cdot 6 \mathrm{H}_{2} \mathrm{O}\right)$ methanol solution with a molar concentration of $0.69 \mathrm{mmol} / \mathrm{L}$ and $100 \mathrm{~mL} 2$ methylimidazole methanol solution with a molar concentration of $36 \mathrm{mmol} / \mathrm{L}$ were mixed into the above solution at the same time and stirred for $2 \mathrm{~h}$ at natural temperature. After being separated by centrifugation and washing with methanol several times, and dried at $60^{\circ} \mathrm{C}$, the resulting powder was obtained.

\subsubsection{Synthesis of $\mathrm{Fe}_{2} \mathrm{O}_{3}$ nanotube@ ZIF-67/Ni-Co LDH}

First, $50 \mathrm{mg}$ of as-synthesized $\mathrm{Fe}_{2} \mathrm{O}_{3} @ Z$ ZIF-67 was ultrasonically dispersed in $30 \mathrm{~mL}$ of ethanol. Then $7.48 \mathrm{~g}$ nickel nitrate hexahydrate $\left(\mathrm{Ni}\left(\mathrm{NO}_{3}\right)_{2} \cdot 6 \mathrm{H}_{2} \mathrm{O}\right)$ was added into the above solution and stirred for $1 \mathrm{~h}$. The obtained product was centrifuged and repeatedly cleaned with ethanol, and dried in a vacuum oven at $60{ }^{\circ} \mathrm{C}$ for $12 \mathrm{~h}$.

\subsubsection{Synthesis of NC-FNCP}

The NC-FNCP was prepared by a facile low-temperature phosphatization process. Based on the phosphorous loading and electrochemical performance, the optimum ratio of phosphorous precursors to $\mathrm{Fe}_{2} \mathrm{O}_{3} @ Z I F-67 / \mathrm{Ni}-\mathrm{Co} \mathrm{LDH}$ precursors was about 10:1. Briefly, $20 \mathrm{mg}$ of $\mathrm{Fe}_{2} \mathrm{O}_{3} @ \mathrm{NiCo}-\mathrm{LDH}$ and $200 \mathrm{mg}$ of $\mathrm{NaH}_{2} \mathrm{PO}_{2} \cdot \mathrm{H}_{2} \mathrm{O}$ were put in the downstream and upstream side of the tubular furnace and then heated at $350{ }^{\circ} \mathrm{C}$ for $2 \mathrm{~h}$ under $\mathrm{N}_{2}$ flow. For comparison, single hollow structure Ni-Co-P nanocages and Fe-P nanotubes were also prepared with a similar method.

\subsection{Materials characterization}

The phases and crystal structure of the synthesized samples were analyzed by X-ray diffraction (XRD, Rigaku D/max-2500, Cu K $\alpha$ $(\lambda=0.1542 \mathrm{~nm}))$ with the $2 \theta$ degree from $10^{\circ}$ to $80^{\circ}$ at a scanning 
rate of $8 \% \mathrm{~min}$. The morphology and microstructure of the samples were examined via scanning electron microscopy (SEM, JEOL JSM-6700F, $5 \mathrm{~kW}$ ) and transmission electron microscopy (TEM, 200CX, $200 \mathrm{kV}$ ). High-resolution transmission electron microscopy (HRTEM) was performed on a JEOL JEM-2100F electron microscope operating at $200 \mathrm{kV}$. The surface analysis and the composition of samples were implemented by X-ray photoelectron spectroscopy (XPS) using an X-ray photoelectron spectrometer with a monochromatic $\mathrm{Al} \mathrm{K} \alpha$ radiation. The component of the samples were analysed by energy dispersive spectroscopy (EDS, Hitachi SU-70) and inductively coupled plasma optical emission spectroscopy (ICP-OES, PerkinElmer ICP 2100). The surface area and porosity analyzer (Quantachrome, USA Qudrasorb SI) was used to assess pore volume, pore size and surface area of the samples via the Brunauer-Emmett-Teller (BET) surface areas and pore-size distribution curves.

\subsection{Electrochemical measurements}

All the half-cell electrochemical measurements were carried out using a standard three-electrode system on a CHI660E workstation. The Ni foam coated with catalysts, carbon rod, and standard $\mathrm{Hg} / \mathrm{HgO}$ were used as working, counter, and reference electrodes, respectively. The water and urea splitting were performed at a two-electrode cell using the NC-FNCP as both the anode and cathode. The OER and water electrolysis were conducted in $1 \mathrm{M} \mathrm{KOH}$, while UOR and urea electrolysis was exerted in $1 \mathrm{M} \mathrm{KOH}$ with $0.5 \mathrm{M}$ urea. The catalyst ink was prepared by dispersing $6.0 \mathrm{mg}$ of as-prepared catalysts in a mixed solution of $110 \mu \mathrm{L}$ of ethanol, $330 \mu \mathrm{L}$ of distilled water, and $40 \mu \mathrm{L}$ of naphthol. Then dropped $120 \mu \mathrm{L}$ of the catalyst ink on the NF substrate and dried at room temperature. All potentials reported were calibrated to the potential versus RHE using the Eq. (1)

$$
E(\mathrm{~V} \text { vs. } \mathrm{RHE})=E(\mathrm{~V} \text { vs. } \mathrm{Hg} / \mathrm{HgO})+0.0592 \times \mathrm{pH}+0.098 \mathrm{~V}
$$

The linear scanning voltammetry (LSV) curves were measured with a sweeping rate of $5 \mathrm{mV} / \mathrm{s}$. The polarization curve was replotted as voltage vs. log current density to obtain the Tafel plot. By fitting the linear portion of the Tafel plot to the Tafel equation

$$
\eta=a+b \log |j|
$$

$\eta$ refers to the overpotential, $b$ is the Tafel slope and $a$ denotes the intercept. Cyclic voltammetry (CV) measurement was implemented at scan rates of $10-100 \mathrm{mV} / \mathrm{s}$ and the double-layer capacitance $\left(C_{\mathrm{dl}}\right)$ was calculated from the $\mathrm{CV}$ plot. Electrochemical impedance spectroscopy (EIS) was conducted at a frequency range from $10^{5}$ to $0.01 \mathrm{~Hz}$ with an amplitude of $5 \mathrm{mV}$. Turnover frequency (TOF) was calculated according to the following equation

$$
\mathrm{TOF}=J \times A /(z \times F \times n)
$$

where $J$ is the current density at a specific potential $\left(\mathrm{A} / \mathrm{cm}^{2}\right), A$ is the surface area of the Ni foam $\left(1 \mathrm{~cm}^{2}\right), z$ is the number of electrons transferred in the OER and UOR $(z=4$ in the OER, and $z=6$ in the UOR), $F$ is the Faraday constant $(96,485 \mathrm{C} / \mathrm{mol})$, and $n$ is the total number of moles of the active metal centers of the catalysts.

\section{Results and discussion}

The synthetic processes of NC-FNCP were schematically illustrated in Fig. 1. Firstly, $\mathrm{Fe}_{2} \mathrm{O}_{3}$ nanotubes were prepared by a facile hydrothermal method [48]. Secondly, the regular $\mathrm{Fe}_{2} \mathrm{O}_{3}$ nanotube@ZIF-67 composite nanostructure was formed by the nucleation and growth on the surface of PVP-modified $\mathrm{Fe}_{2} \mathrm{O}_{3}$

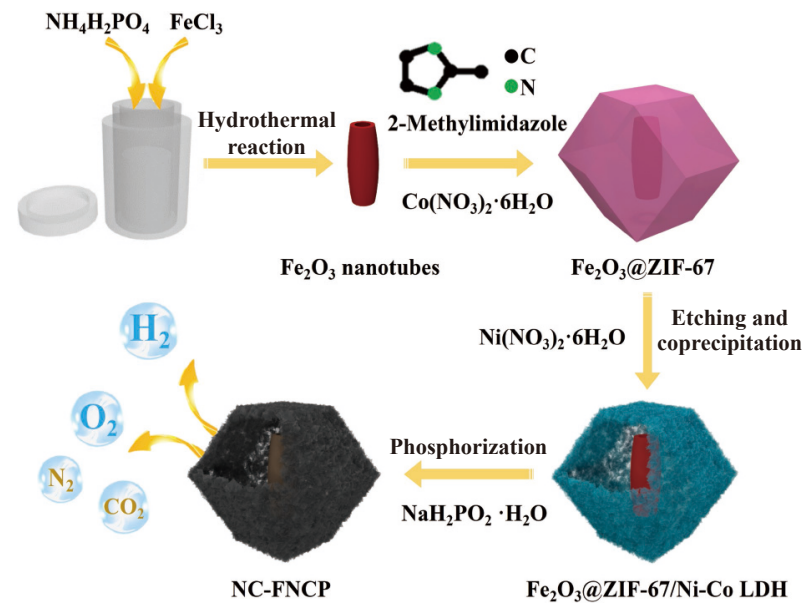

Figure 1 Schematic illustration of the synthesis of NC-FNCP.

nanotubes. Then the $\mathrm{Fe}_{2} \mathrm{O}_{3}$ nanotube@ZIF-67 was further used to react with $\mathrm{Ni}\left(\mathrm{NO}_{3}\right)_{2} \cdot 6 \mathrm{H}_{2} \mathrm{O}$, where ZIF-67 acts as a self-sacrificing template. During this process, the generated protons from the hydrolysis of $\mathrm{Ni}^{2+}$ ions etch the ZIF-67 nanoparticles, meanwhile, the released $\mathrm{Co}^{2+}$ ions from ZIF-67 are partially oxidized. As a result, $\mathrm{Co}^{2+} / \mathrm{Co}^{3+}$ in situ co-precipitate with $\mathrm{Ni}^{2+}$ as $\mathrm{Ni}-\mathrm{Co} \mathrm{LDH}$ layers around the ZIF-67 dodecahedron. $\mathrm{As}^{\mathrm{Co}^{2+}}$ continues to flow outwards, the solid ZIF-67 becomes vulnerable and eventually generates the outer hollow nanocages [30]. Finally, the $\mathrm{Fe}_{2} \mathrm{O}_{3} @ Z I F-$ $67 / \mathrm{Ni}-\mathrm{Co} \mathrm{LDH}$ are chemically converted into NC-FNCP by $\mathrm{NaH}_{2} \mathrm{PO}_{2} \cdot \mathrm{H}_{2} \mathrm{O}$ treatment at $350^{\circ} \mathrm{C}$ for $2 \mathrm{~h}$ in an inert atmosphere. As a result, the nested hollow NC-FNCP composed of Fe-Co-Ni tri-metal phosphides and nitrogen-doped carbon is achieved.

The precursors and the final product NC-FNCP were characterized by SEM and TEM images. The synthesized $\mathrm{Fe}_{2} \mathrm{O}_{3}$ displays a uniform hollow nanotube morphology with a smooth and tidy surface (Figs. 2(a) and 2(b)). The length of the nanotubes is about $200-400 \mathrm{~nm}$, and the outer and inner diameters of the nanotube are 90-110 and 40-80 nm, respectively (Fig. 2(c)). $\mathrm{Fe}_{2} \mathrm{O}_{3}$ nanotube@ZIF-67 has an outer dodecahedral polyhedral structure with a very uniform size (ca. 400-600 nm) (Figs. 2(d)-2(f)), which is the same as that of the pure ZIF-67. $\mathrm{Fe}_{2} \mathrm{O}_{3}$ nanotubes and $\mathrm{Fe}_{2} \mathrm{O}_{3}$ nanotube@ZIF-67 were also further studied by XRD (Fig. S1 in the Electronic Supplementary Material (ESM)). After the etching of ZIF-67 and the coprecipitate process of $\mathrm{Co}^{2+} / \mathrm{Co}^{3+}$ ions with $\mathrm{Ni}^{2+}$, the as-formed $\mathrm{Fe}_{2} \mathrm{O}_{3}$ nanotube@ZIF-67/Ni-Co LDH inherits the dodecahedron morphology and the dimension of $\mathrm{Fe}_{2} \mathrm{O}_{3}$ nanotube@ZIF-67 but shows rough surfaces (Fig.2(g)). TEM unambiguously reveals that the ZIF-67 layers convert to the hollow dodecahedron nanostructures and the surface is assembled by $\mathrm{LDH}$ nanoflakes. As a result, with a hollow $\mathrm{Fe}_{2} \mathrm{O}_{3}$ nanotube inside, the etched product shows a unique nested hollow architecture (Figs. 2(h) and 2(i)). XRD patterns still show slight diffractions of ZIF-67 (Fig. S2 in the ESM), demonstrating that ZIF-67 was not thoroughly transformed into Ni-Co LDH during the etching process.

After phosphatization treatment, the SEM (Fig. 3(a)) and TEM (Figs. 3(b) and 3(c) images illustrated that the obtained NC-FNCP maintained similar morphologies with that of $\mathrm{Fe}_{2} \mathrm{O}_{3}$ nanotube@ZIF-67/Ni-Co LDH precursor. Similar phenomenon could also be found in the synthesis of $\mathrm{FeP}_{4}$ nanotubes (Fig. S3 in the ESM) and Ni-Co-P nanocages (Fig. S4 in the ESM). However, careful observations indicated that the outer shell of NC-FNCP was composed of amorphous carbon-decorated nanoparticles with size of ca. $5 \mathrm{~nm}$ (Figs. 3(d)-3(f)). These nanoparticles were interconnected with each other, which was beneficial for the electron transfer. HRTEM measurements were further applied to give more detailed structural information of NC-FNCP. The 

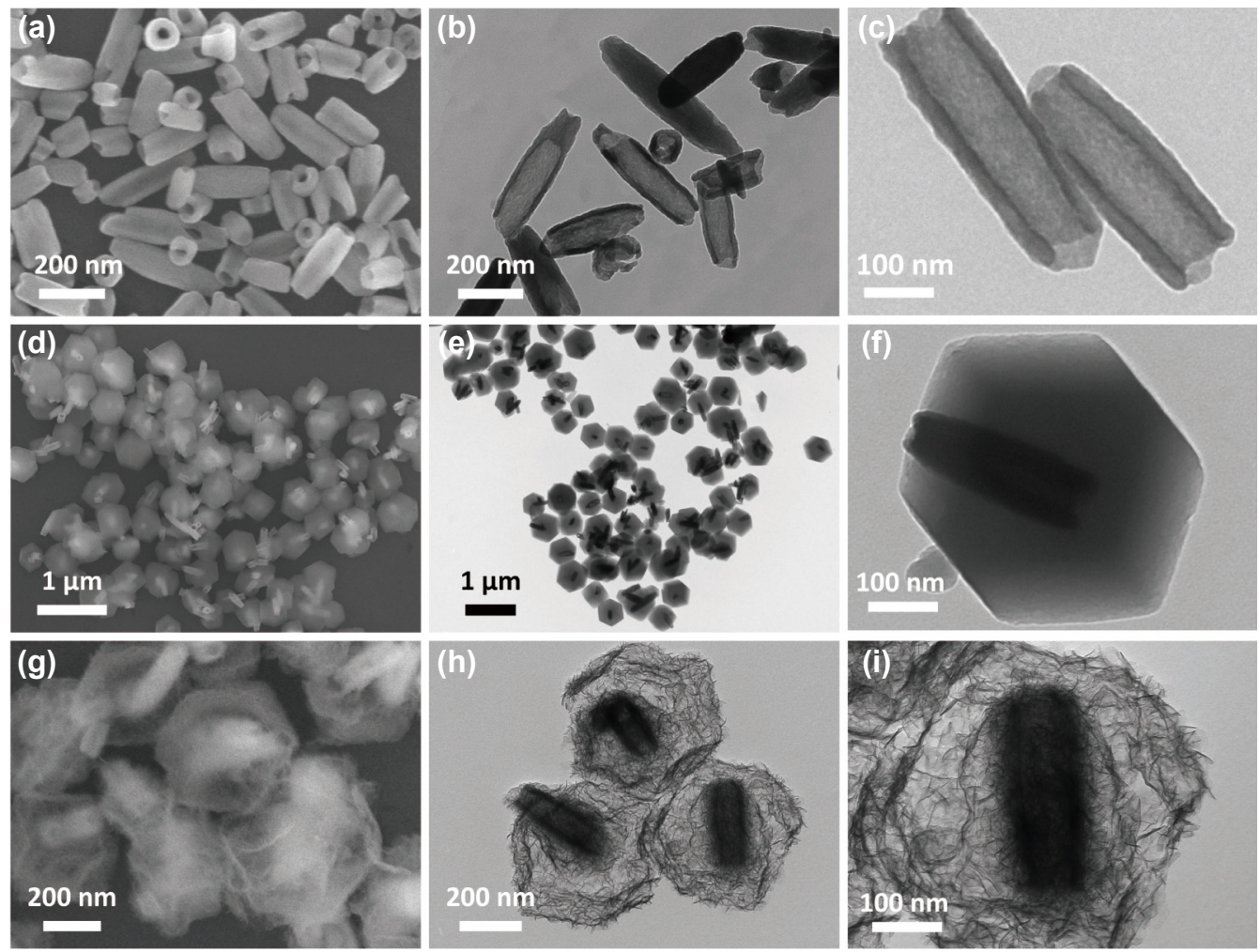

Figure 2 (a) SEM, (b) and (c) TEM images of the $\mathrm{Fe}_{2} \mathrm{O}_{3}$ nanotubes. (d) SEM, (e) and (f) TEM images of $\mathrm{Fe}_{2} \mathrm{O}_{3}$ nanotube@ZIF-67. (g) SEM, (h) and (i) TEM images of $\mathrm{Fe}_{2} \mathrm{O}_{3}$ nanotube@ZIF-67/Ni-Co LDH.
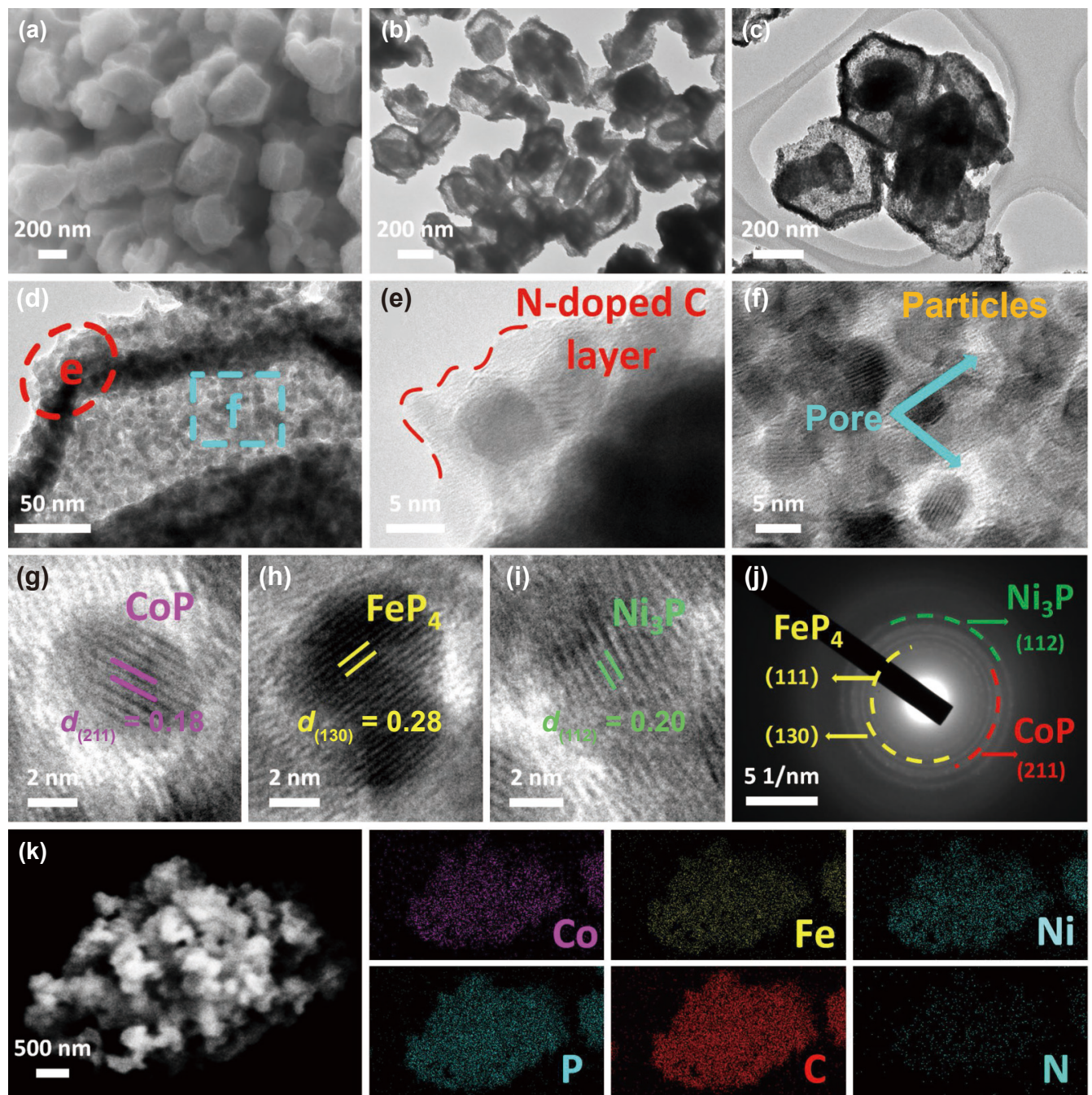

Figure 3 (a) SEM, (b) and (c) TEM images of NC-FNCP. (d)-(i) HRTEM images of NC-FNCP. (j) SAED image of NC-FNCP and (k) EDS mapping images of NC-FNCP. 
interplanar spacings of $0.28,0.20$, and $0.19 \mathrm{~nm}$ were consistent with the (211) plane of $\mathrm{CoP}$, (130) plane of $\mathrm{FeP}_{4}$, and the (112) plane of $\mathrm{Ni}_{3} \mathrm{P}$, respectively (Figs. $\left.3(\mathrm{~g})-3(\mathrm{i})\right)$. Selected area electron diffraction (SAED) patterns (Fig. 3(j)) confirmed the existence of three phosphide phases, e.g., $\mathrm{CoP}, \mathrm{Ni}_{3} \mathrm{P}$, and $\mathrm{FeP}_{4}$. Elemental mapping images were obtained to further demonstrate the surface elements and their distribution. Figure $3(\mathrm{k})$ displays the EDS mapping images revealing those elements of $\mathrm{Co}, \mathrm{Fe}, \mathrm{Ni}, \mathrm{P}, \mathrm{C}$, and $\mathrm{N}$ for NC-FNCP. Energy-dispersive X-ray spectroscopy (EDX) result showed that the $\mathrm{Fe} / \mathrm{Co} / \mathrm{Ni}$ mass ratio in the NC-FNCP yolkshelled structure was about 1:0.45:0.72 (Fig. S5 in the ESM). The chemical composition of the sample was further measured using ICP-OES (Table S1 in the ESM). The $\mathrm{Fe} / \mathrm{Co} / \mathrm{Ni}$ atomic ratio was about 1:0.26:0.52, which was very close to the EDX result. Those results revealed that the homogeneous hybrid of the $\mathrm{FeP}_{4}$ and NiCo-P phases. To evaluate the specific surface areas and the pore size distribution of NC-FNCP, $\mathrm{N}_{2}$ adsorption-desorption isotherm was recorded in Fig. S6 in the ESM. The sample showed a nearly type-IV signal with the BET surface area of $14.4 \mathrm{~cm}^{3} / \mathrm{g}$. The corresponding Barrett-Joyner-Halenda (BJH) curve delivered that NC-FNCP presented a well-defined mesoporous structure.

XRD analysis was revealed in Fig. 4(a), the peaks of the NCFNCP are corresponding with the standard card CoP (JCPDS No. 29-0497), $\mathrm{FeP}_{4}$ (JCPDS No. 32-0471) and $\mathrm{Ni}_{3} \mathrm{P}$ (JCPDS No. 340501 ), respectively. Typical diffraction peaks located at $31.6^{\circ}, 36.3^{\circ}$, $46.2^{\circ}, 48.1^{\circ}, 56.0^{\circ}$ and $56.7^{\circ}$ are corresponding to the crystal faces of CoP (011), (111), (112), (211), (020) and (301). Diffraction peaks at $31.8^{\circ}, 35.8^{\circ}, 38.2^{\circ}, 39.5^{\circ}, 43.4^{\circ}, 46.0^{\circ}$ and $53.9^{\circ}$ can be attributed to the crystal faces of $\mathrm{FeP}_{4}$ at (130), (131), (112), (201), (221), (132) and (241). And the remaining characteristic diffraction peaks centered at $41.8^{\circ}, 45.2^{\circ}, 46.6^{\circ}, 50.6^{\circ}$ and $52.7^{\circ}$ represent lattice planes of (231), (112), (240), (141), (222), and (132) in $\mathrm{Ni}_{3} \mathrm{P}$, respectively.

XPS measurement was actualized to study the surface composition and bonding state of the final product NC-FNCP $[49,50]$. The XPS survey spectra of NC-FNCP (Fig. S7 in the ESM) contain elements of $\mathrm{Ni}, \mathrm{Co}, \mathrm{Fe}, \mathrm{P}, \mathrm{C}, \mathrm{N}$, and O. The XPS spectra of each element are presented in Figs. 4(b)-4(f). As for $\mathrm{Ni}$ 2p (Fig. 4(b)), two peaks with a binding energy difference of about $17.7 \mathrm{eV}$, namely $\mathrm{Ni} 2 \mathrm{p}_{1 / 2}(870.9 \mathrm{eV})$ and $\mathrm{Ni} 2 \mathrm{p}_{3 / 2}(853.2 \mathrm{eV})$, confirming the predominance of $\mathrm{Ni}^{2+}$ valence [51]. The peaks at
856.6 and $875.5 \mathrm{eV}$ belong to $\mathrm{Ni}^{3+}$, while the other two peaks around 857.0 and $882.6 \mathrm{eV}$ are assigned to satellite peaks [52]. As for Co $2 p$ (Fig. 4(c)), the peaks of 793.7 and $778.6 \mathrm{eV}$ from $\mathrm{Co}^{3+}$, and the peaks 781.1 and $797.8 \mathrm{eV}$ from $\mathrm{Co}^{2+}$ correspond to $2 \mathrm{p}_{1 / 2}$ and $2 \mathrm{p}_{3 / 2}$ of Co $2 \mathrm{p}$, respectively [20]. The remaining peaks of 803.6 and $786.3 \mathrm{eV}$ are satellite peaks [53]. Moreover, no peaks matched with zero-valence nickel and cobalt are confirmed, indicating that the outer shell of NC-FNCP is completely covered by $\mathrm{Ni}_{3} \mathrm{P}$ and CoP. For the Fe XPS spectra (Fig. $4(\mathrm{~d})$ ), the peaks of Fe $2 \mathrm{p}_{3 / 2}$ $(710.2$ and $713.2 \mathrm{eV})$ and $\mathrm{Fe} 2 \mathrm{p}_{1 / 2}(724.3$ and $727.8 \mathrm{eV})$ are observed, corresponding with the higher oxidation states of $\mathrm{Fe}^{2+}$ and $\mathrm{Fe}^{3+}$, respectively. The slight peak centered at $706.7 \mathrm{eV}$ correspond to the Fe species in NC-FNCP [19]. Compared to Ni$\mathrm{Co}-\mathrm{P}$, the binding energy of Co $2 \mathrm{p}$ and $\mathrm{Ni} 2 \mathrm{p}$ of NC-FNCP were negatively shift of 0.6 and $0.5 \mathrm{eV}$, suggesting the synergy interaction between $\mathrm{FeP}_{4}, \mathrm{Ni}_{3} \mathrm{P}$ and $\mathrm{CoP}$ (Fig. $\mathrm{S} 8$ in the ESM). The three peaks at $284.5,285.7$ and $288.8 \mathrm{eV}$ of $\mathrm{C}$ 1s spectra (Fig. 4(e)) indicated the presence of $\mathrm{C}-\mathrm{C}, \mathrm{C}=\mathrm{N}$ and $\mathrm{O}=\mathrm{C}-\mathrm{O}$ functional groups for NC-FNCP. In P 2p spectra (Fig. 4(f)), the fitting peaks centered at 129.6 and $129.1 \mathrm{eV}$ corresponding to the $\mathrm{P} 2 \mathrm{p}_{1 / 2}$ and $\mathrm{P}$ $2 \mathrm{p}_{3 / 2}$ of metal phosphides, while the peak at around $133.6 \mathrm{eV}$ belongs to the $\mathrm{P}-\mathrm{O}$ bonds, which can attribute to partial oxidation of metal phosphides NC-FNCP [54].

The OER performance of NC-FNCP was assessed in $1.0 \mathrm{M}$ $\mathrm{KOH}$ by using a traditional three-electrode cell. For comparison, hollow Ni-Co-P nanocages, Fe-P nanotubes, and commercial $\mathrm{RuO}_{2}$ catalysts were also evaluated with the same condition. Figure 5(a) presents the LSV curves of different samples with IR correction. The NC-FNCP electrode shows a lower overpotential of $287 \mathrm{mV}$ at $50 \mathrm{~mA} / \mathrm{cm}^{2}$ for OER, which is superior to $\mathrm{RuO}_{2}(306$ $\mathrm{mV}$ ), Ni-Co-P $(339 \mathrm{mV})$, and $\mathrm{FeP}_{4}(368 \mathrm{mV}$ ) electrodes. As shown in Table S2 in the ESM, compared to the other related materials, the OER performance of NC-FNCP is outstanding. Moreover, the catalytic activity of NC-FNCP is also higher than all compared samples at the high current density. Such excellent performance may result from the synergistic combination of tricomponent metal catalytic centers ( $\mathrm{Fe}, \mathrm{Co}$, and $\mathrm{Ni}$ ) effectively facilitating the charge transfer efficiency. Tafel slope was calculated according to the LSV curves to describe the kinetics of OER (Fig. 5(b)). Tafel slope for NC-FNCP is $51.2 \mathrm{mV} /$ decade, smaller than those for Ni-Co-P (77.1 $\mathrm{mV} /$ decade) and $\mathrm{FeP}_{4}(96.1$
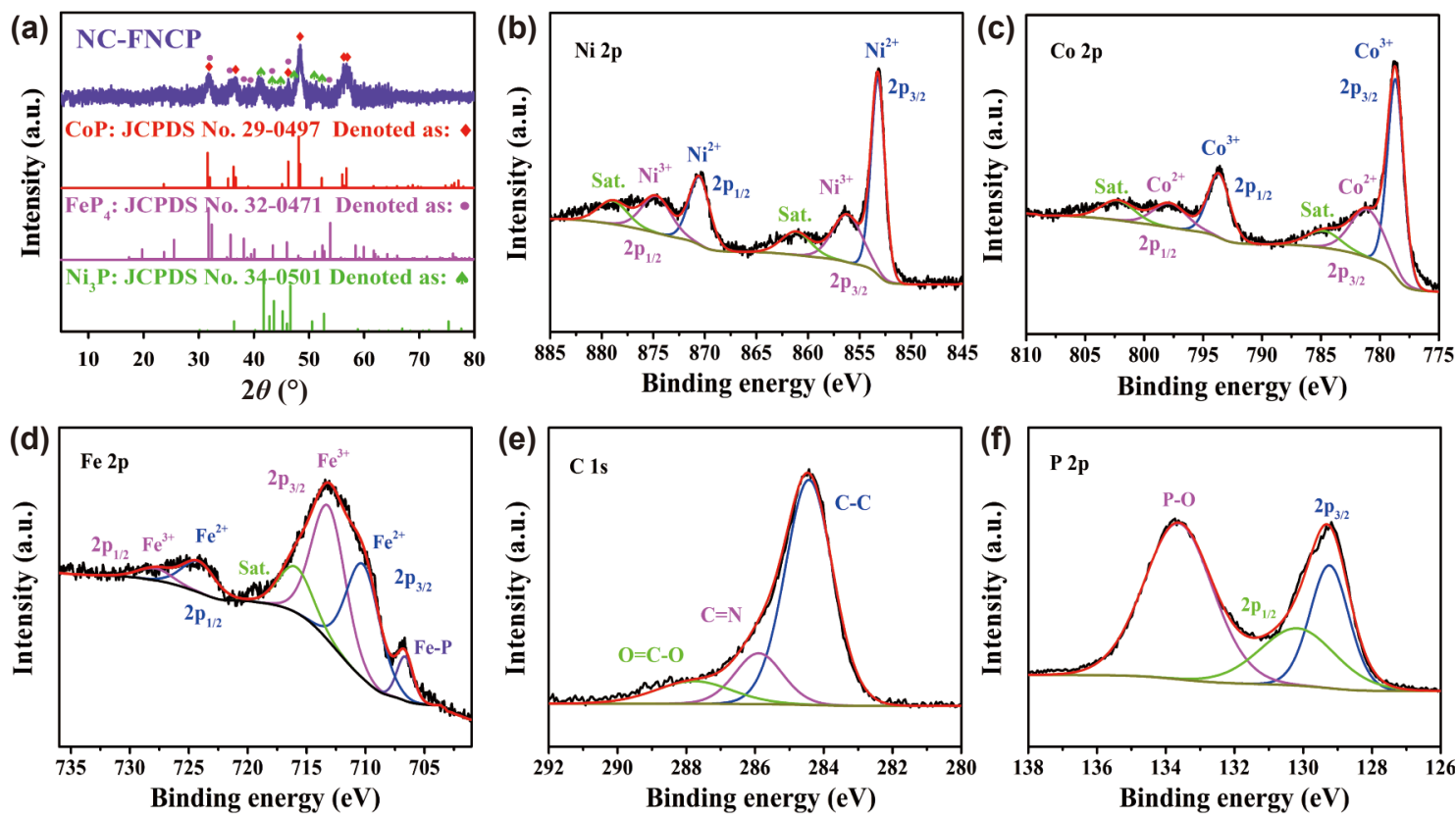

Figure 4 (a) XRD patterns; XPS spectra (b) Ni 2p; (c) Co 2p; (d) Fe 2p; (e) C 1s and (f) P 2p of NC-FNCP. 

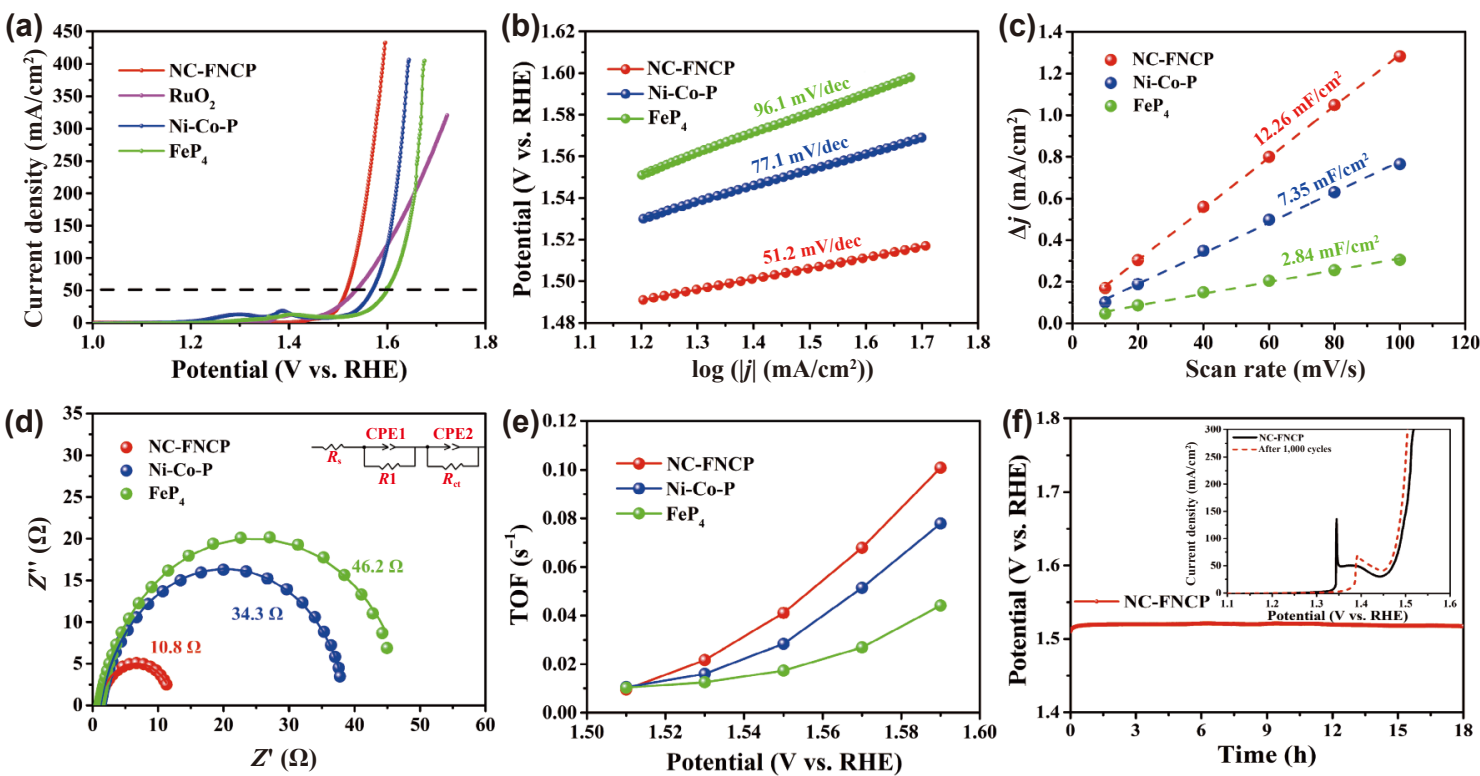

Figure 5 Electrochemical measurements for the OER in $1 \mathrm{M} \mathrm{KOH}$ solution. (a) LSV curves and (b) corresponding Tafel plots of the $\mathrm{RuO}_{2}, \mathrm{FeP}_{4}, \mathrm{Ni}-\mathrm{Co}-\mathrm{P}$ and NCFNCP samples. (c) The fitted $C_{\mathrm{dl}}$ of the above samples, (d) Nyquist plots and (e) TOF values of the above samples. (f) The Chronopotentiometry curves of the NCFNCP at $25 \mathrm{~mA} / \mathrm{cm}^{2}$ inset of (f) showing LSV curves of the NC-FNCP before and after 1,000 CV cycles.

$\mathrm{mV} /$ decade), hinting at the favorable OER reaction kinetics of NCFNCP. The double-layer capacitances $\left(C_{\mathrm{dl}}\right)$ were analyzed from CV curves to estimate the electrochemically active surface areas. Derived from the CV at different scan rates (Fig. S9 in the ESM), the extracted $C_{\mathrm{dl}}$ of NC-FNCP, Ni-Co-P and $\mathrm{FeP}_{4}$ were 12.36, 7.35 and $2.84 \mathrm{mF} / \mathrm{cm}^{2}$, respectively (Fig. 5(c)). The larger $C_{\mathrm{dl}}$ of NCFNCP further confirms the advantage of the nested hollow architectures. The Nyquist plots derived from EIS were applied to reveal the charge transfer resistance $\left(R_{\mathrm{ct}}\right)$ at the electrolyte/catalyst interface (Fig. 5(d)). As shown in Table S3 in the ESM, the $R_{\mathrm{ct}}$ of NC-FNCP is the smallest among all the samples. This result demonstrated that NC-FNCP has a faster charge transfer rate and favorable OER kinetics. TOF as a considerable kinetic parameter can be used to depict the intrinsic activities of electrocatalysts [17]. It was supposed that all the metal sites in NC-FNCP are electrocatalytically active. According to the TOF equation, the TOF results are described in Fig. 5(e), NC-FNCP shows the highest TOF $\left(0.041 \mathrm{~s}^{-1}\right.$ at $\left.\eta=1.55 \mathrm{~V}\right)$ in the OER process. These results are identified with the Tafel slope analysis. To investigate the stability of the NC-FNCP electrode for practical applications, coherent $\mathrm{CV}$ and long-term chronopotentiometry were performed. Two LSV curves show slight differences and the performance even improved after the 1,000 CV cycles (Fig. 5(f)). In addition, the chronopotentiometry measurements demonstrate the outstanding stability of the NC-FNCP electrode after continuous OER operation for $18 \mathrm{~h}$ at the current density of $25 \mathrm{~mA} / \mathrm{cm}^{2}$.

To ensure the genuine active species of NC-FNCP during the OER and UOR processes, the electrodes after OER/UOR longterm stability measurement were evaluated by XPS analysis. As shown in Figs. S10(b)-S10(d) in the ESM, all peaks in the regions of Co 2p, Ni 2p, and Fe 2p XPS spectra clearly showed that trivalent oxyhydroxide became a predominant metal species after OER electrolysis. Compared with the original sample, all the peaks (Co 2p, Ni 2p, and Fe 2p) shift toward more positive binding energies, and the area ratio of the relative peaks of $\mathrm{Co}^{3+} /$ $\mathrm{Co}^{2+}, \mathrm{Ni}^{3+} / \mathrm{Ni}^{2+}$, and $\mathrm{Fe}^{3+} / \mathrm{Fe}^{2+}$ increase, indicating that those metals were oxidized to higher valence states. Meanwhile, those metal phosphides disappear, which is consistent with the disappearance of metallic P with binding energy of 129.1 and $130.2 \mathrm{eV}$ (Fig. S10(e) in the ESM) signal and the appearance of lattice oxygen signal with a binding energy of $529.5 \mathrm{eV}$ (Fig. S10(f) in the ESM).
Thus, we conclude that at least the surface of the catalyst is oxidized to oxide/(oxy) hydroxide species after the electrochemical process, and the in-situ phase transformation may contribute to the high OER activity and good stability of the heterometallic phosphide catalyst. The surface layer of these oxide/(oxy) hydroxide species was in amorphous forms (Fig. S11 in the ESM), which was in good agreement with previous studies. Additionally, the SEM image recorded after the OER stability test exhibits that the original architectures of the catalyst are still well maintained (Fig. S12 in the ESM), which in part justify the cycle stability of NC-FNCP.

To assess the main active centers of the as-prepared phosphides, DFT calculations were further performed to calculate the adsorption/desorption energies of oxygen-containing intermediates $\left(\mathrm{OH}^{*}, \mathrm{O}^{*}\right.$, and $\left.\mathrm{OOH}^{*}\right)$ at the interface of catalysts. In consideration of the HRTEM results, the facets of (130), (112), and (211) were employed for $\mathrm{FeP}_{4}, \mathrm{Ni}_{3} \mathrm{P}$, and $\mathrm{CoP}$, respectively (Figs. S13-S15 in the ESM). Based on the diagram in Fig. S16 and Table S4 in the ESM, the rate-determining step for the three catalysts was the conversion of $\mathrm{O}^{*}$ to $\mathrm{OOH}^{\star}$ species during the OER process. It can be seen that the $\mathrm{CoP}$ exhibited a significantly smaller $\Delta G$ value of $1.762 \mathrm{eV}$ for the rate-determining step (RDS) than that of $\mathrm{Ni}_{3} \mathrm{P}(2.536 \mathrm{eV})$ and $\mathrm{FeP}_{4}(2.704 \mathrm{eV})$, confirming a more favorable OER kinetics on the CoP model. Moreover, one can found that all four steps on the surface of $\mathrm{CoP}$ are thermodynamically uphill at potential $U=0 \mathrm{~V}$. When $U$ increases to $1.815 \mathrm{~V}$, the highest $\Delta G$ value of the OER elementary steps decreases to $0 \mathrm{eV}$, which implied that the entire OER process could proceed spontaneously over this potential. Based on these results, we speculate that the Co sites may be the main active metal centers of NC-FNCP.

The above results indicate that NC-FNCP shows obvious potential toward OER, which motivates further study on NCFNCP for UOR. UOR was carried out using the same threeelectrode setup as OER except that the different concentrations ( 0 , 0.33 and $0.5 \mathrm{M}$ ) of urea were added to $1.0 \mathrm{M} \mathrm{KOH}$ as the electrolyte. LSV curves show that the anodic current increased extensively after adding urea (Fig. S17 in the ESM). Moreover, the needed operation voltage is $1.41 \mathrm{~V}$ to drive $50 \mathrm{~mA} / \mathrm{cm}^{2}$ with $1.0 \mathrm{M}$ $\mathrm{KOH}+0.5 \mathrm{M}$ urea, which is $111 \mathrm{mV}$ smaller than that of the OER process in the same condition. This means that UOR consumes less energy [55]. For the comparison, the further experiments were 
measured in the condition of $1 \mathrm{M} \mathrm{KOH}+0.5 \mathrm{M}$ urea. As depicted in Fig. 6(a), the NC-FNCP electrode only needs operation voltages of $1.37,1.44$, and $1.48 \mathrm{~V}$ (vs. RHE), to attain current densities of 10,100 , and $200 \mathrm{~mA} / \mathrm{cm}^{2}$, respectively, which are far superior to the control cases by using Ni-Co-P $(1.41,1.49$, and $1.54 \mathrm{~V})$ and $\mathrm{FeP}_{4}(1.44,1.54$, and $1.57 \mathrm{~V})$. The performance of NC-FNCP is also preferable to those of the recently-related electrocatalysts (Table S5 in the ESM). As an important parameter to evaluate kinetics, the Tafel slope also supports the above results (Fig. 6(b)) [23]. The Tafel slope of NC-FNCP is $35.79 \mathrm{mV} / \mathrm{dec}$, which is smaller than that of Ni-Co-P $(75.85 \mathrm{mV} / \mathrm{dec})$ and $\mathrm{FeP}_{4}(97.26$ $\mathrm{mV} / \mathrm{dec}$ ). Compared with OER, these low Tafel slope values indicate that the energy efficiency of hydrogen generation is improved for UOR [53]. The larger $C_{\mathrm{dl}}$ (Fig. 6(c)) derived from CV of NC-FNCP (Fig. S18 in the ESM) compared to those of control samples indicated that the nested hollow NC-FNCP could afford more accessible active reaction sites for UOR. It was further verified by the favorable charge transport process of NC-FNCP revealed by EIS measurement (Fig. 6(d)). A smaller $R_{\mathrm{ct}}(25.4 \Omega$ ) is found for the NC-FNCP electrodes by fitting the Nyquist plot (Table S3 in the ESM). These results indicated that the nitrogendoped carbon can accelerate electron transfer and the nested hollow architectures are beneficial to promote electrolyte transfer. In addition, the TOF of NC-FNCP was identified as $0.82 \mathrm{~s}^{-1}$ at $\eta=$ $1.36 \mathrm{~V}$ (Fig. 6(e)), larger than those of the controls, demonstrating the synergistic effects of the combination of tricomponent metal catalytic centers. Furthermore, chronopotentiometry measurement was obtained to assess the UOR durability for the NC-FNCP electrode (Fig. 6(f)). The potential of 95\% was maintained after $12 \mathrm{~h}$ continuous urea electrolysis at $10 \mathrm{~mA} / \mathrm{cm}^{2}$, suggesting the excellent UOR stability for the NC-FNCP electrode. To further investigate genuine species during the catalytic UOR, XPS analysis was also employed to evaluate the catalyst after the UOR stability test (Fig. S19 in the ESM). It was found that the change trends in the binding energies of Co 2p, Ni 2p, Fe 2p, P 2p, and $\mathrm{O} 1 \mathrm{~s}$ were similar to the case of OER, which implies that the surface oxidation also occurred during UOR, and this surface layer is amorphous as seen in the HRTEM image (Fig. S20 in the ESM). In addition, as shown in Fig. S21 in the ESM, the structure of the catalyst also remains well. It was then convinced that the synergic effects of these active species and well-maintained structures ensure the UOR performances.

The hydrogen evolution reaction (HER) performance of NCFNCP was also obtained in $1.0 \mathrm{M} \mathrm{KOH}$ with and without $0.5 \mathrm{M}$ urea, and the results are depicted in Fig. S22 in the ESM. It was found that the potentials required for HER have a difference of 41 $\mathrm{mV}$ to reach the current density of $50 \mathrm{~mA} / \mathrm{cm}^{2}$ in $1.0 \mathrm{M} \mathrm{KOH}$ with and without $0.5 \mathrm{M}$ urea. However, with the increase of current density, the presence of urea shows little effect on HER performance. According to Figs. S23(a) and S23(c) in the ESM, the NC-FNCP electrode at $10 \mathrm{~mA} / \mathrm{cm}^{2}$ requires relatively low potentials of 145 and $157 \mathrm{mV}$ in $1.0 \mathrm{M} \mathrm{KOH}$ with and without 0.5 $\mathrm{M}$ urea, respectively. The potentials of NC-FNCP were also lower than those of Ni-Co-P and $\mathrm{FeP}_{4}$ electrodes. Additionally, Tafel slopes obtained from LSV curves are shown in Figs. S23(b) and S23(d) in the ESM, the NC-FNCP electrode exhibits the smallest Tafel slope compared with Ni-Co-P and $\mathrm{FeP}_{4}$ electrodes, indicating its favorable HER kinetics.

All the above results imply that NC-FNCP has potential for overall water and urea electrolysis. In consideration of the practical application and energy conversion, a two-electrode electrolyzer was set up using NC-FNCP as both anode and cathode in $1 \mathrm{M}$ $\mathrm{KOH}$ with and without the addition of $0.5 \mathrm{M}$ urea. As shown in Fig. 7(a), to deliver the current density of $10 \mathrm{~mA} / \mathrm{cm}^{2}$, the cell voltage of urea electrolysis is $1.52 \mathrm{~V}$, which is about $110 \mathrm{mV}$ lower than that of water electrolysis. The required cell voltages to attain higher current densities $\left(20,50\right.$, and $\left.100 \mathrm{~mA} / \mathrm{cm}^{2}\right)$ are also much lower than those required for water electrolysis (Fig. 7(b)), implying the urea electrolysis process consumes less energy. In addition, the long-term durability of water (Fig. 7(c)) and urea (Fig. 7(d)) electrolysis was examined by chronopotentiometry measurements. As for urea electrolysis, the NC-FNCP\|NC-FNCP electrode maintained a high voltage of $96 \%$ after $20 \mathrm{~h}$ at 10 $\mathrm{mA} / \mathrm{cm}^{2}$. Those results demonstrate that NC-FNCP has superior performance overall water and urea splitting as well as good stability.

The high performances of nested hollow architectures of NCFNCP for water and urea electrolysis mainly due to the following reasons: (1) The synergistic combination of tricomponent metal catalytic centers $(\mathrm{Fe}, \mathrm{Co}$, and $\mathrm{Ni}$ ) effectively altering the electronic structure and facilitating the charge transfer efficiency. (2) The nested porous hollow architectures with large specific surface areas
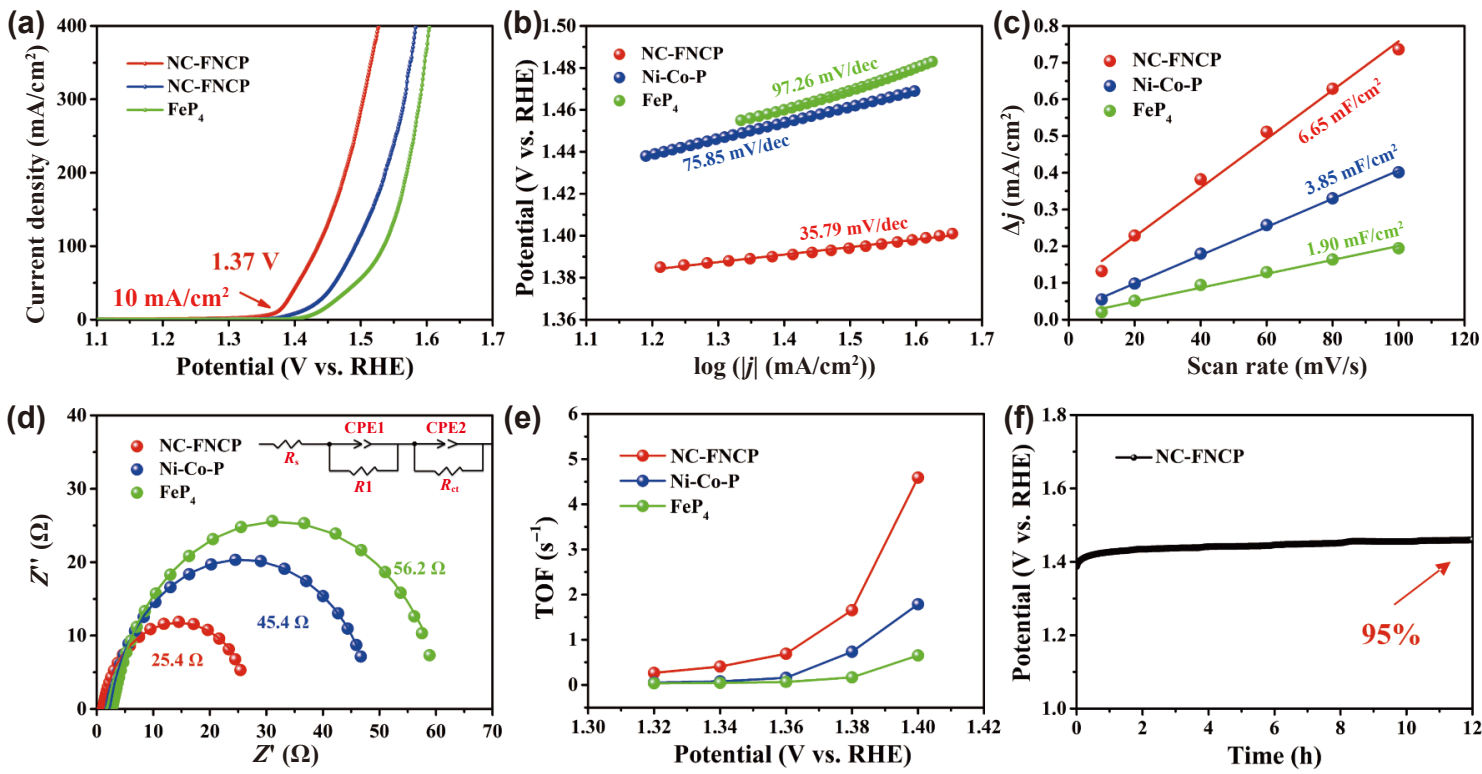

Figure 6 Electrochemical measurements for the UOR in $1 \mathrm{M} \mathrm{KOH}$ and $0.5 \mathrm{M}$ urea solution. (a) LSV curves and (b) corresponding Tafel plots of the FeP 4 , Ni-Co-P and NC-FNCP samples. (c) the fitted $C_{\mathrm{dl}}$ of the above samples, (d) Nyquist plots and (e) TOF values of the above samples. (f) The Chronopotentiometry curves of the $\mathrm{NC}-\mathrm{FNCP}$ at $10 \mathrm{~mA} / \mathrm{cm}^{2}$. 

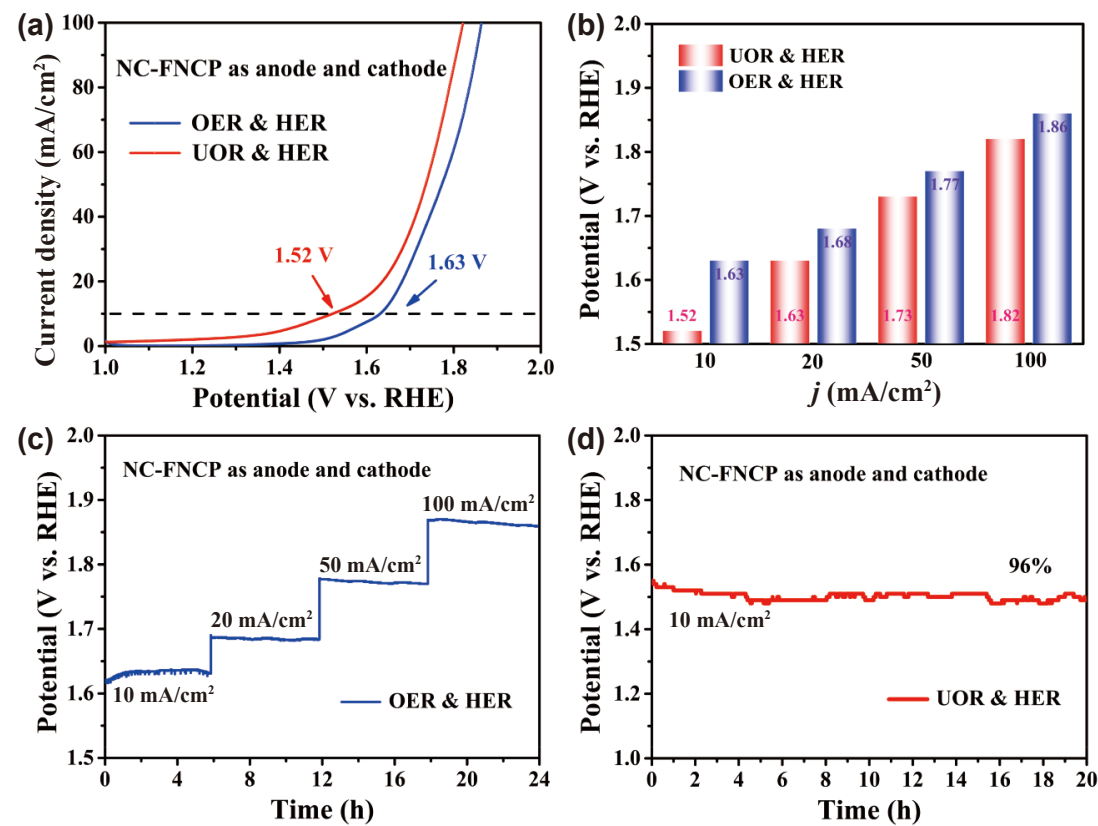

Figure 7 (a) LSV curves for the NC-FNCP\|NC-FNCP electrode in $1.0 \mathrm{M} \mathrm{KOH}$ with (blue line) and without (red line) $0.5 \mathrm{M}$ urea. (b) Comparison of the required voltage at different current densities for overall water and urea electrolysis. (c) Chronopotentiometry plots of water electrolysis implemented at different current densities. (d) Chronopotentiometry plots of urea electrolysis implemented at the current density of $10 \mathrm{~mA} / \mathrm{cm}^{2}$.

are conducive to the full contact of the electrolyte/electrode and facilitate the release of bubbles. (3) The existence of $\mathrm{N}$-doped carbon composition can improve electronic conductivity and facilitate rapid electron/mass transport. Thus, the strategy of building the nested hollow architectures with multicomponent TMPs could be extended to other metal phosphides for electrocatalysis.

\section{Conclusions}

In summary, nested hollow architectures of NC-FNCP were successfully fabricated through a facile method. Due to the unique structural features and trimetallic compositions, NC-FNCP shows superior boosting electrocatalytic activities by reducing the resistance for ion transportation, accelerating the diffusion of gases, and enhancing the utilization of electroactive species compared to the single hollow Ni-Co-P nanocages and $\mathrm{FeP}_{4}$ nanotubes. As a result, NC-FNCP requires a low overpotential of $248 \mathrm{mV}$ and $1.37 \mathrm{~V}$ (vs. RHE) to achieve the current density of $10 \mathrm{~mA} / \mathrm{cm}^{2}$ for OER and UOR, respectively. When used as a bifunctional catalyst toward urea-assisted hydrogen generation, the NC-FNCP requires a cell voltage of $1.52 \mathrm{~V}$ to deliver $10 \mathrm{~mA} / \mathrm{cm}^{2}$ with long-term electrochemical durability for $20 \mathrm{~h}$. This work exhibits an inexpensive catalyst system with multiplecomponent and multi-shell hollow nanostructures, thus paving a path to devise the high-performance bifunctional electrodes for the energy-efficient combination of hydrogen generation and sewage treatment.

\section{Acknowledgements}

The work was supported by the National Natural Science Foundation of China (No. 21601120), the Science and Technology Commission of Shanghai Municipality (Nos. 17ZR1410500 and 19ZR1418100), Science and Technology Program of Shanghai (No. 21010500300), STINT Joint China-Sweden Mobility Project (No. CH2017-7243), and Swedish Government strategic faculty grant in material science (SFO, MATLIU) in Advanced Functional Materials (AFM) (VR Dnr. 5.1-2015-5959). We also appreciate the High-Performance Computing Center of Shanghai University, and Shanghai Engineering Research Center of
Intelligent Computing System (No. 19DZ2252600) for providing the computing resources and technical support.

Funding note: Open access funding provided by Linköping University.

Electronic Supplementary Material: Supplementary material (TEM images of $\mathrm{FeP}_{4}$ nanotubes and Ni-Co-P nanocages; EDX and ICP-OES analysis of NC-FNCP; CV curves of different catalysts in $1.0 \mathrm{M} \mathrm{KOH}$ and $1.0 \mathrm{M} \mathrm{KOH}+0.5 \mathrm{M}$ urea; XPS spectroscopy of the NC-FNCP after OER and UOR stability test; the calculated Gibbs free-energy diagram) is available in the online version of this article at https://doi.org/10.1007/s12274-021-3810-4.

Open Access This article is licensed under a Creative Commons Attribution 4.0 International License, which permits use, sharing, adaptation, distribution and reproduction in any medium or format, as long as you give appropriate credit to the original author(s) and the source, provide a link to the Creative Commons licence, and indicate if changes were made.

The images or other third party material in this article are included in the article's Creative Commons licence, unless indicated otherwise in a credit line to the material. If material is not included in the article's Creative Commons licence and your intended use is not permitted by statutory regulation or exceeds the permitted use, you will need to obtain permission directly from the copyright holder.

To view a copy of this licence, visit http://creativecommons. org/licenses/by/4.0/.

\section{References}

[1] Zhang, J. Y.; He, T.; Wang, M. D.; Qi, R. J.; Yan, Y.; Dong, Z. H.; Liu, H. F.; Wang, H. M.; Xia, B. Y. Energy-saving hydrogen production coupling urea oxidation over a bifunctional nickelmolybdenum nanotube array. Nano Energy 2019, 60, 894-902.

[2] Wang, Y.; Sun, L. Z.; Lu, L. G.; Xu, D. D.; Hao, Q. L.; Liu, B. A sequential template strategy toward hierarchical hetero-metal phosphide hollow nanoboxes for electrocatalytic oxygen evolution. J. Mater. Chem. A 2021, 9, 3482-3491.

[3] Cui, B. H.; Hu, Z.; Liu, C.; Liu, S. L.; Chen, F. S.; Hu, S.; Zhang, J. 
F.; Zhou, W.; Deng, Y. D.; Qin, Z. B. et al. Heterogeneous lamellaredged $\mathrm{Fe}-\mathrm{Ni}(\mathrm{OH})_{2} / \mathrm{Ni}_{3} \mathrm{~S}_{2}$ nanoarray for efficient and stable seawater oxidation. Nano Res. 2021, 14, 1149-1155.

[4] Xie, H. P.; Lan, C.; Chen, B.; Wang, F. H.; Liu, T. Noble-metal-free catalyst with enhanced hydrogen evolution reaction activity based on granulated Co-doped Ni-Mo phosphide nanorod arrays. Nano Res. 2020, 13, 3321-3329.

[5] Fang, M.; Dong, G. F.; Wei, R. J.; Ho, J. C. Hierarchical nanostructures: Design for sustainable water splitting. Adv. Energy Mater. 2017, 7, 1700559.

[6] Qiu, Z.; Ma, Y.; Edström, K.; Niklasson, G. A.; Edvinsson, T. Controlled crystal growth orientation and surface charge effects in self-assembled nickel oxide nanoflakes and their activity for the oxygen evolution reaction. Int. J. Hydrog. Energy 2017, 42, 28397-28407.

[7] Hunter, B. M.; Gray, H. B.; Müller, A. M. Earth-abundant heterogeneous water oxidation catalysts. Chem. Rev. 2016, 116, 14120-14136.

[8] Tang, C.; Zhang, R.; Lu, W. B.; Wang, Z.; Liu, D. N.; Hao, S.; Du, G.; Asiri, A. M.; Sun, X. P. Energy-saving electrolytic hydrogen generation: $\mathrm{Ni}_{2} \mathrm{P}$ nanoarray as a high-performance non-noble-metal electrocatalyst. Angew. Chem., Int. Ed. 2017, 56, 842-846.

[9] Ding, Y.; Miao, B. Q.; Li, S. N.; Jiang, Y. C.; Liu, Y. Y.; Yao, H. C.; Chen, Y. Benzylamine oxidation boosted electrochemical watersplitting: Hydrogen and benzonitrile co-production at ultra-thin $\mathrm{Ni}_{2} \mathrm{P}$ nanomeshes grown on nickel foam. Appl. Catal. B: Environ. 2020, $268,118393$.

[10] Tuomi, S.; Santasalo-Aarnio, A.; Kanninen, P.; Kallio, T. Hydrogen production by methanol-water solution electrolysis with an alkaline membrane cell. J. Power Sources 2013, 229, 32-35.

[11] Wang, L. Q.; Bevilacqua, M.; Filippi, J.; Fornasiero, P.; Innocenti, M.; Lavacchi, A.; Marchionni, A.; Miller, H. A.; Vizza, F. Electrochemical growth of platinum nanostructures for enhanced ethanol oxidation. Appl. Catal. B: Environ. 2015, 165, 185-191.

[12] Zhu, X. J.; Dou, X. Y.; Dai, J.; An, X. D.; Guo, Y. Q.; Zhang, L. D.; Tao, S.; Zhao, J. Y.; Chu, W. S.; Zeng, X. C. et al. Metallic nickel hydroxide nanosheets give superior electrocatalytic oxidation of urea for fuel cells. Angew. Chem., Int. Ed. 2016, 55, 12465-12469.

[13] Chen, S.; Duan, J. J.; Vasileff, A.; Qiao, S. Z. Size fractionation of two-dimensional sub-nanometer thin manganese dioxide crystals towards superior urea electrocatalytic conversion. Angew. Chem., Int. Ed. 2016, 55, 3804-3808.

[14] Zhao, J. X.; Ren, X.; Han, Q. Z.; Fan, D. W.; Sun, X.; Kuang, X.; Wei, Q.; Wu, D. Ultra-thin wrinkled $\mathrm{NiOOH}-\mathrm{NiCr}_{2} \mathrm{O}_{4}$ nanosheets on $\mathrm{Ni}$ foam: An advanced catalytic electrode for oxygen evolution reaction. Chem. Commun. 2018, 54, 4987-4990.

[15] Wang, G. X.; Chen, J. X.; Li, Y.; Jia, J. C.; Cai, P. W.; Wen, Z. H. Energy-efficient electrolytic hydrogen production assisted by coupling urea oxidation with a pH-gradient concentration cell. Chem. Commun. 2018, 54, 2603-2606.

[16] Liu, Z.; Zha, M.; Wang, Q.; Hu, G. Z.; Feng, L. G. Overall watersplitting reaction efficiently catalyzed by a novel bi-functional $\mathrm{Ru} / \mathrm{Ni}_{3} \mathrm{~N}-\mathrm{Ni}$ electrode. Chem. Commun. 2020, 56, 2352-2355.

[17] Liu, H. P.; Zhu, S. L.; Cui, Z. D.; Li, Z. Y.; Wu, S. L.; Liang, Y. Q. $\mathrm{Ni}_{2} \mathrm{P}$ nanoflakes for the high-performing urea oxidation reaction: Linking active sites to a UOR mechanism. Nanoscale 2021, 13, $1759-1769$.

[18] Li, Q.; Li, X. R.; Gu, J. W.; Li, Y. L.; Tian, Z. Q.; Pang, H. Porous rod-like $\mathrm{Ni}_{2} \mathrm{P} / \mathrm{Ni}$ assemblies for enhanced urea electrooxidation. Nano Res. 2021, 14, 1405-1412.

[19] Yan, L.; Sun, Y. L.; Hu, E. L.; Ning, J. Q.; Zhong, Y. J.; Zhang, Z. Y.; Hu, Y. Facile in-situ growth of $\mathrm{Ni}_{2} \mathrm{P} / \mathrm{Fe}_{2} \mathrm{P}$ nanohybrids on $\mathrm{Ni}$ foam for highly efficient urea electrolysis. J. Colloid Interf. Sci. 2019, 541, 279-286.

[20] Wang, T.; Wu, H. M.; Feng, C. Q.; Zhang, L.; Zhang, J. J. MoP@NiCo-LDH on nickel foam as bifunctional electrocatalyst for high efficiency water and urea-water electrolysis. J. Mater. Chem. A 2020, 8, 18106-18116.

[21] Zheng, J. L.; Wu, K. L.; Lyu, C. J.; Pan, X.; Zhang, X. F.; Zhu, Y. C.; Wang, A. D.; Lau, W. M.; Wang, N. Electrocatalyst of two- dimensional $\mathrm{CoP}$ nanosheets embedded by carbon nanoparticles for hydrogen generation and urea oxidation in alkaline solution. Appl. Surf. Sci. 2020, 506, 144977.

[22] Han, L.; Yu, T. W.; Lei, W.; Liu, W. W.; Feng, K.; Ding, Y. L.; Jiang, G. P.; Xu, P.; Chen, Z. W. Nitrogen-doped carbon nanocones encapsulating with nickel-cobalt mixed phosphides for enhanced hydrogen evolution reaction. J. Mater. Chem. A 2017, 5, 16568-16572.

[23] Yang, D. W.; Gu, Y.; Yu, X.; Lin, Z. X.; Xue, H. G.; Feng, L. G. Nanostructured $\mathrm{Ni}_{2} \mathrm{P}-\mathrm{C}$ as an efficient catalyst for urea electrooxidation. ChemElectroChem 2018, 5, 659-664.

[24] Sha, L. N.; Yin, J. L.; Ye, K.; Wang, G.; Zhu, K.; Cheng, K.; Yan, J.; Wang, G. L.; Cao, D. X. The construction of self-supported thorny leaf-like nickel-cobalt bimetal phosphides as efficient bifunctional electrocatalysts for urea electrolysis. J. Mater. Chem. A 2019, 7, 9078-9085.

[25] Ji, Z. J.; Liu, J.; Deng, Y.; Zhang, S. T.; Zhang, Z.; Du, P. Y.; Zhao, Y. L.; Lu, X. Q. Accurate synergy effect of Ni-Sn dual active sites enhances electrocatalytic oxidation of urea for hydrogen evolution in alkaline medium. J. Mater. Chem. A 2020, 8, 14680-14689.

[26] Yang, D. X.; Su, Z.; Chen, Y. F.; Srinivas, K.; Gao, J. Z.; Zhang, W. L.; Wang, Z. G.; Lin, H. P. Electronic modulation of hierarchical spongy nanosheets toward efficient and stable water electrolysis. Small 2021, 17, 2006881.

[27] Zhang, P.; Lu, X. F.; Nai, J. W.; Zang, S. Q.; Lou, X. W. Construction of hierarchical $\mathrm{Co}-\mathrm{Fe}$ oxyphosphide microtubes for electrocatalytic overall water splitting. Adv. Sci. 2019, 6, 1900576.

[28] Xu, H.; Liao, Y.; Gao, Z. F.; Qing, Y.; Wu, Y. Q.; Xia, L. Y. A branch-like Mo-doped $\mathrm{Ni}_{3} \mathrm{~S}_{2}$ nanoforest as a high-efficiency and durable catalyst for overall urea electrolysis. J. Mater. Chem. A 2021, 9, 3418-3426.

[29] Liang, Z. B.; Qu, C.; Zhou, W. Y.; Zhao, R.; Zhang, H.; Zhu, B. J.; Guo, W. H.; Meng, W.; Wu, Y. X.; Aftab, W. et al. Synergistic effect of Co-Ni hybrid phosphide nanocages for ultrahigh capacity fast energy storage. Adv. Sci. 2019, 6, 1802005.

[30] He, P. L.; Yu, X. Y.; Lou, X. W. Carbon-incorporated nickel-cobalt mixed metal phosphide nanoboxes with enhanced electrocatalytic activity for oxygen evolution. Angew. Chem., Int. Ed. 2017, 56, 3897-3900.

[31] Sha, L. N.; Liu, T. F.; Ye, K.; Zhu, K.; Yan, J.; Yin, J. L.; Wang, G. L.; Cao, D. X. A heterogeneous interface on NiS@ $\mathrm{Ni}_{3} \mathrm{~S}_{2} / \mathrm{NiMoO}_{4}$ heterostructures for efficient urea electrolysis. J. Mater. Chem. A 2020, 8, 18055-18063.

[32] Kaneti, Y. V.; Guo, Y. N.; Septiani, N. L. W.; Iqbal, M.; Jiang, X. C.; Takei, T.; Yuliarto, B.; Alothman, Z. A.; Golberg, D.; Yamauchi, Y. Self-templated fabrication of hierarchical hollow manganesecobalt phosphide yolk-shell spheres for enhanced oxygen evolution reaction. Chem. Eng. J. 2021, 405, 126580.

[33] Adhikari, S.; Kwon, Y.; Kim, D. H. Three-dimensional core-shell structured $\mathrm{NiCo}_{2} \mathrm{O}_{4} @ \mathrm{CoS} / \mathrm{Ni}$-foam electrocatalyst for oxygen evolution reaction and electrocatalytic oxidation of urea. Chem. Eng. J. 2020, 402, 126192.

[34] Zhang, H. B.; Zhou, W.; Dong, J. C.; Lu, X. F.; Lou, X. W. Intramolecular electronic coupling in porous iron cobalt (oxy)phosphide nanoboxes enhances the electrocatalytic activity for oxygen evolution. Energy Environ. Sci. 2019, 12, 3348-3355.

[35] Liu, J. L.; Yang, Y.; Ni, B.; Li, H. Y.; Wang, X. Fullerene-like nickel oxysulfide hollow nanospheres as bifunctional electrocatalysts for water splitting. Small 2017, 13, 1602637.

[36] Sun, H. M.; Xu, X. B.; Yan, Z. H.; Chen, X.; Cheng, F. Y.; Weiss, P $\mathrm{S}$; Chen, J. Porous multishelled $\mathrm{Ni}_{2} \mathrm{P}$ hollow microspheres as an active electrocatalyst for hydrogen and oxygen evolution. Chem. Mater. 2017, 29, 8539-8547.

[37] Shi, J. H.; Qiu, F.; Yuan, W. B.; Guo, M. M.; Lu, Z. H. Nitrogendoped carbon-decorated yolk-shell CoP@FeCoP micro-polyhedra derived from MOF for efficient overall water splitting. Chem. Eng. J. 2021, 403, 126312 .

[38] Li, Y. Z.; Li, S. W.; Hu, J.; Zhang, Y. Y.; Du, Y. C.; Han, X. J.; Liu, X.; Xu, P. Hollow FeCo-FeCoP@C nanocubes embedded in nitrogen-doped carbon nanocages for efficient overall water 
splitting. J. Energy Chem. 2021, 53, 1-8.

[39] Liu, X. P.; Deng, S. F.; Xiao, D. D.; Gong, M. X.; Liang, J. N.; Zhao, T. H.; Shen, T.; Wang, D. L. Hierarchical bimetallic Ni-Co-P microflowers with ultrathin nanosheet arrays for efficient hydrogen evolution reaction over all $\mathrm{pH}$ values. ACS Appl. Mater. Interfaces 2019, 11, 42233-42242.

[40] Wang, J. Z.; Chen, C.; Cai, N.; Wang, M.; Li, H.; Yu, F. Q. High topological tri-metal phosphide of $\mathrm{CoP} @ \mathrm{FeNiP}$ toward enhanced activities in oxygen evolution reaction. Nanoscale 2021, 13, 1354-1363.

[41] Li, F.; Bu, Y. F.; Lv, Z. J.; Mahmood, J.; Han, G. F.; Ahmad, I.; Kim, G.; Zhong, Q.; Baek, J. B. Porous cobalt phosphide polyhedrons with iron doping as an efficient bifunctional electrocatalyst. Small 2017, 13, 1701167.

[42] Hong, W.; Kitta, M.; Xu, Q. Bimetallic MOF-Derived FeCo-P/C nanocomposites as efficient catalysts for oxygen evolution reaction. Small Methods 2018, 2, 1800214.

[43] Pan, Y.; Sun, K. A.; Liu, S. J.; Cao, X.; Wu, K. L.; Cheong, W. C.; Chen, Z.; Wang, Y.; Li, Y.; Liu, Y. Q. et al. Core-shell ZIF-8@ZIF67-derived CoP nanoparticle-embedded $\mathrm{N}$-doped carbon nanotube hollow polyhedron for efficient overall water splitting. J. Am. Chem. Soc. 2018, 140, 2610-2618.

[44] Hu, H.; Guan, B. Y.; Xia, B. Y.; Lou, X. W. Designed formation of $\mathrm{Co}_{3} \mathrm{O}_{4} / \mathrm{NiCo}_{2} \mathrm{O}_{4}$ double-shelled nanocages with enhanced pseudocapacitive and electrocatalytic properties. J. Am. Chem. Soc. 2015, 137, 5590-5595.

[45] Wang, C. S.; Chen, W. B.; Yuan, D.; Qian, S. S.; Cai, D. D.; Jiang, J. T.; Zhang, S. Q. Tailoring the nanostructure and electronic configuration of metal phosphides for efficient electrocatalytic oxygen evolution reactions. Nano Energy 2020, 69, 104453.

[46] Chen, L.; Xu, H. Y.; Li, L. E.; Wu, F. F.; Yang, J.; Qian, Y. T. A comparative study of lithium-storage performances of hematite: Nanotubes vs. nanorods. J. Power Sources 2014, 245, 429-435.

[47] Jia, C. J.; Sun, L. D.; Yan, Z. G.; You, L. P.; Luo, F.; Han, X. D.;
Pang, Y. C.; Zhang, Z.; Yan, C. H. Single-crystalline iron oxide nanotubes. Angew. Chem., Int. Ed. 2005, 44, 4328-4333.

[48] Zheng, P. L.; Zhang, Y.; Dai, Z. F.; Zheng, Y.; Dinh, K. N.; Yang, J.; Dangol, R.; Liu, X. B.; Yan, Q. Y. Constructing multifunctional heterostructure of $\mathrm{Fe}_{2} \mathrm{O}_{3} @ \mathrm{Ni}_{3} \mathrm{Se}_{4}$ nanotubes. Small 2018, 14, 1704065 .

[49] Du, C.; Yang, L.; Yang, F. L.; Cheng, G. Z.; Luo, W. Nest-like $\mathrm{NiCoP}$ for highly efficient overall water splitting. ACS Catal. 2017, 7, 4131-4137.

[50] Hu, E. L.; Feng, Y. F.; Nai, J. W.; Zhao, D.; Hu, Y.; Lou, X. W. Construction of hierarchical Ni-Co-P hollow nanobricks with oriented nanosheets for efficient overall water splitting. Energy Environ. Sci. 2018, 11, 872-880.

[51] Zhang, J. T.; Yu, L.; Chen, Y.; Lu, X. F.; Gao, S. Y.; Lou, X. W. Designed formation of double-shelled Ni-Fe layered-doublehydroxide nanocages for efficient oxygen evolution reaction. $A d v$. Mater. 2020, 32, 1906432.

[52] Wang, Y.; Wang, S. B.; Lou, X. W. Dispersed nickel cobalt oxyphosphide nanoparticles confined in multichannel hollow carbon fibers for photocatalytic $\mathrm{CO}_{2}$ reduction. Angew. Chem., Int. Ed. 2019, 58, 17236-17240.

[53] Wang, Z. L.; Liu, W. J.; Hu, Y. M.; Guan, M. L.; Xu, L.; Li, H. P.; Bao, J.; Li, H. M. Cr-doped CoFe layered double hydroxides: Highly efficient and robust bifunctional electrocatalyst for the oxidation of water and urea. Appl. Catal. B: Environ. 2020, 272, 118959.

[54] Ma, F. X.; Xu, C. Y.; Lyu, F. C.; Song, B.; Sun, S. C.; Li, Y. Y.; Lu, J.; Zhen, L. Construction of FeP hollow nanoparticles densely encapsulated in carbon nanosheet frameworks for efficient and durable electrocatalytic hydrogen production. $A d v$. Sci. 2019, 6, 1801490.

[55] Wang, C.; Lu, H. L.; Mao, Z. Y.; Yan, C. L.; Shen, G. Z.; Wang, X. F. Bimetal Schottky heterojunction boosting energy-saving hydrogen production from alkaline water via urea electrocatalysis. Adv. Funct. Mater. 2020, 30, 2000556. 